\title{
Satisfaction of Chronic Illness Patients at Felege Hiwot Referral Hospital, Bahir Dar City, Northwest Ethiopia
}

\author{
Molla Gedefaw ${ }^{1}$, Fisseha Setargie ${ }^{1}$, Worku Awoke ${ }^{2}$ \\ ${ }^{1}$ GAMBY College of Medicine and Health Sciences, Bahir Dar, Ethiopia \\ ${ }^{2}$ College of Medicine and Health Sciences, Bahir Dar University, Bahir Dar, Ethiopia \\ Email: "Mollagedefaw@yahoo.com
}

Received 25 August 2014; revised 25 September 2014; accepted 25 October 2014

Copyright (C) 2014 by authors and Scientific Research Publishing Inc.

This work is licensed under the Creative Commons Attribution International License (CC BY). http://creativecommons.org/licenses/by/4.0/

cC) (i) Open Access

\begin{abstract}
Introduction: Patient satisfaction is a popular way of evaluating quality of health care given in health facilities. This study was done to assess the level of chronic illness Patients' Satisfaction in Felege Hiwot Referral Hospital, Bahir Dar City, Ethiopia. Method: Cross-sectional study was conducted by involving 415 patients using systematic sampling method at Felege Hiwot referral hospital, Bahir Dar City, Ethiopia from $1^{\text {st }}$ September, 2012 to $2^{\text {nd }}$ November, 2012. Structured questionnaire was data collection tool. The questionnaire was prepared in English. It was translated to Amharic and back to English. Discrepancies in the translation were resolved by mutual agreement with the research team. Pre-testing was done prior to the actual data collection process on a sample of 20 respondents and modified accordingly. The study was approved by ethics review board of Bahir Dar University. The collected data were checked for completeness and consistency before being coded, entered and analyzed using SPSS version 19. Result: The overall level of satisfaction of chronic illness patients in this hospital was 242 (58.3\%) which is lower as compared to other local studies in Ethiopia. More than $\mathbf{4 0 \%}$ of the patients were not satisfied with the service. Conclusion and Recommendations: The current level of patients' satisfaction in the hospital is totally unacceptable care for a referral hospital situated in the capital city of a region in which more than 20 million people reside. Therefore, there is a need to revisit care given to chronic illness patients, and appropriate strategy should be designed to address the lifelong care needs of patients with chronic illness in our set up.
\end{abstract}

\section{Keywords}

Satisfaction, Chronic Illness, Ethiopia

${ }^{*}$ Corresponding author.

How to cite this paper: Gedefaw, M., Setargie, F. and Awoke, W. (2014) Satisfaction of Chronic Illness Patients at Felege Hiwot Referral Hospital, Bahir Dar City, Northwest Ethiopia. Open Journal of Epidemiology, 4, 217-223.

http://dx.doi.org/10.4236/ojepi.2014.44028 


\section{Introduction}

Measuring and reporting on patient satisfaction with health care has become a major industry [1]. Patient satisfaction is one of the desired outcomes of health care and it is directly related with utilization of health services [2]. Satisfied patients are more likely to utilize health services, comply with medical treatment, and continue with the health care providers [3]. Studies showed that the overall level of patient satisfaction and associated factors were varied in different countries and settings, for example 75.08\% in Tertiary Care Hospital in Nagpur [4], 66.8\% in Southeastern Nigeria [5] and in South Africa 51.9\% for midwifery service [6] were reported about overall patients' satisfaction.

Ethiopia previous studies showed that, there were differences in different localities with regard to the overall patients' satisfactions; $89.1 \%$ in Jimma [7], 80.1\% in Hawassa [8], 54.1\% in Harari region [9] and $18.0 \%$ of the patients at the public hospitals were very satisfied, $54.1 \%$ and $47.9 \%$ were just satisfied in Addis Ababa [10]. This study was done to assess the level Patients' Satisfaction in Felege Hiwot Referral Hospital, Bahir Dar City, Ethiopia.

\section{Methods}

\subsection{Study Design}

Cross-sectional study was conducted at Felege Hiwot referral hospital, Bahir Dar City, Ethiopia from $1^{\text {st }}$ September 2012 to $2^{\text {nd }}$ November 2012. Bahir Dar City is the capital city of the Amhara National Regional State located at about $565 \mathrm{~km}$ northwest of Addis Ababa (the capital city of Ethiopia).

\subsection{Sample Size Determination and Sampling Procedure}

Targeted groups of patients for this study were diabetes mellitus, hypertension, and asthmatic patients. The sample size was determined by using a single population proportion formula, which took the proportion of overall satisfaction as $43.6 \%$ [11], with a margin of error of 0.05 at the $95 \%$ confidence interval (CI). Adding $10 \%$ nonresponse rate, the final sample size was calculated to be 415 patients. From the hospital pervious report about patient flow, average number of adult patients with chronic illness who visited the hospital was 77 per day. Therefore the number of patients who visited the hospital was estimated for the study period; then sampling fraction for selecting the study participants was determined by dividing with total estimated number of patients during the data collection period to the total sample size which was calculated to be five. The first study participant was selected by lottery method among the list from one to five; the next study participant was identified systematically in every $5^{\text {th }}$ intervals until the required sample size was achieved.

\subsection{Data Collection Procedure and Quality Assurance}

A structured questionnaire was prepared according to the objectives of the study and the local situation of the study area in English language. Then the questionnaire was translated to Amharic and back to English to assure consistency of the tool. Discrepancies in the translation were resolved by mutual agreement with the research team. Pre-testing was conducted on 20 respondents at a referral hospital with similar settings.

\subsection{Data Management and Data Analysis}

The collected data were checked for completeness and consistency before being coded, entered and analyzed using SPSS version 19. Descriptive analysis using frequency distribution and percentages were calculated.

\subsection{Ethical Consideration}

The research approved by Research Ethics Review Board of Bahir Dar University. Permission to conduct the study was also obtained from Health Bureau of Amhara National Regional State, and Felege Hiwote referral hospital. During data collection, the purpose of the study was clearly explained to the participants, and informed oral consent was obtained. Confidentiality and privacy was maintained.

\section{Result}

\subsection{Socio Demographic Characteristics of the Respondents}

A total of 415 adult patients having chronic illness were involved for this study. As shown in Table 1, 54.7\% of 
the respondents were male, $43.4 \%$ were above 44 years old, $44.3 \%$ were married, and $40 \%$ never attended formal education and $60.7 \%$ were urban dwellers (Table 1 ).

\subsection{Patients' Experience}

Patients' experience was assessed using 14 items. These items were about the quality of care, its convenience and the medical expense. Majority (74\%) of the respondents had experienced long waiting time for physical examination. Moreover, about $44 \%$ of the respondents were having long waiting time to get prescribed medications in pharmacy. About $64.6 \%$ of the respondents complained of inconvenient location of the hospital pharmacy.

More than $70 \%$ of study participants claimed that the cost of lab tests-blood and urine-was affordable while $55.2 \%$ of the patients claimed that the cost for X-ray test was not affordable.

Nearly $90 \%$ of study participants rated treatment provided by medical doctor as good. Moreover, nearly $70 \%$ of study participants also claimed that medical doctors give chance to patients to ask questions. However, $56.1 \%$ of the respondents claimed that nurses were not skilled in using medical equipment. Besides, about $65 \%$ of study participants complained that hospital officers did not give due attention to concerns of patients (Table 2).

Table 1. Socio demographic characteristics of respondents at FHRH, Bahir Dar City, North Western Ethiopia, 2012.

\begin{tabular}{|c|c|c|c|}
\hline Variables & Categories & $\mathbf{N}$ & $\%$ \\
\hline \multirow[t]{2}{*}{ Sex } & Male & 227 & 54.7 \\
\hline & Female & 188 & 45.3 \\
\hline \multirow[t]{4}{*}{ Age } & $15-24$ & 72 & 17.3 \\
\hline & $25-34$ & 85 & 20.5 \\
\hline & $35-44$ & 78 & 18.8 \\
\hline & $>44$ & 180 & 43.4 \\
\hline \multirow[t]{4}{*}{ Marital status } & Single & 93 & 22.4 \\
\hline & Married & 184 & 44.3 \\
\hline & Widowed & 92 & 22.2 \\
\hline & Divorced/Separated & 46 & 11.1 \\
\hline \multirow[t]{4}{*}{ Education } & Never attended school & 166 & 40 \\
\hline & Primary and junior education & 64 & 15.4 \\
\hline & High school education & 63 & 15.2 \\
\hline & Diploma and above & 122 & 29.4 \\
\hline \multirow[t]{4}{*}{ Occupation } & Self dependent & 90 & 21.7 \\
\hline & Government employed & 103 & 24.8 \\
\hline & Non-government employed & 22 & 5.3 \\
\hline & Merchant, farmers and others & 200 & 48.2 \\
\hline \multirow[t]{4}{*}{ Family income } & $<525$ Eth Birr & 135 & 32.6 \\
\hline & 525 - 2500 Eth Birr & 100 & 24.1 \\
\hline & 2501 - 5500 Eth Birr & 108 & 26 \\
\hline & >5501 Eth Birr & 72 & 17.3 \\
\hline \multirow[t]{2}{*}{ Address } & Urban & 252 & 60.7 \\
\hline & Rural & 163 & 39.3 \\
\hline
\end{tabular}


Table 2. Experience of patients concerning heath care services at the OPD of FHRH, Bahir Dar City, North West Ethiopia, $2012(n=415)$.

\section{Experiences of Patients}

\section{Experience to health care services}

Waiting time for physical examination was long

Waiting time at pharmacy was long

Place for receiving the medicine was in convenient

Place for receiving the treatment was in adequate

Schedule was appropriate

Receiving medical services from one department to another department in OPD was difficult

Medical expense

The cost of urine was affordable

The cost of X-ray affordable

The cost of blood examination was affordable

Quality of care

Services by doctor was good

Availability of Prescribed medicine in pharmacy

Nurse was skilled in using medical equipments

Doctor gave you an opportunity to ask about your illness

Hospital officers listened to your problem attentively
308 (74.2)

369 (88.9)

$\begin{array}{cc}307(74) & 108(26) \\ 182(43.9) & 233(56.1) \\ 268(64.6) & 147(35.4) \\ 173(41.7) & 242(58.3) \\ 151(36.4) & 264(63.6) \\ 308(74.2) & 107(25.8)\end{array}$

186 (44.8)

$107(25.8)$

281 (67.7)

134 (32.3)

316 (76.1)

99 (23.9\%)

182 (43.9)

233 (56.1)

290 (69.9)

125 (30.1)

147 (35.4)

\subsection{Accessibility of Health Care Services at Outpatients Department}

About $50 \%$ of the respondents claimed that they travel more than 10 kilometers to reach the hospital. For about $70 \%$ of the study participants accessing public transport was not a problem. About $55 \%$ of study participants claimed to spent 10 birr or more for public transport.

More than $55 \%$ of the study participants claimed that the information provided to patients was inadequate. (Table 3).

\subsection{Attitude of Study Participants towards Structural and Process Indicators of Health Service Quality}

The structural areas include physical facilities, and medical equipments. The process areas include: services provided by deferent categories (doctors, nurses, registration, and laboratory). The level of the patient satisfaction towards OPD services was measured using 19 items with five ikert's scale. The scale had five grades which include strongly agreed, agreed, not agreed, disagreed and strongly disagreed. As a result, the mean score of total satisfaction was $59.7 \%$.

The finding of this assessment is displayed in Table 4. As shown in the table, major segment of study participants rated the structural aspect of the hospital (physical facilities, and medical equipments) negatively (not agreed, disagreed, or strongly disagreed). Except for laboratory cost, the process aspects which were related to services rendered by different categories of health professionals were rated positively (strongly agreed or agreed).

\subsection{Overall Satisfaction}

The overall level of patients' satisfaction was categorized into two categories: satisfied and unsatisfied. The 
Table 3. Responses of study participants to accessibility assessment items, FRH, North West Ethiopia, $2012(\mathrm{n}=415)$.

\begin{tabular}{|c|c|c|}
\hline Accessibility to health care services & Number & Percent \\
\hline \multicolumn{3}{|l|}{ Distance from hospital } \\
\hline Less than or equal to $10 \mathrm{~km}$ & 204 & $49.2 \%$ \\
\hline Greater than $10 \mathrm{~km}$ & 211 & $50.8 \%$ \\
\hline \multicolumn{3}{|l|}{ Access to public transport to hospital } \\
\hline Yes & 295 & $71.1 \%$ \\
\hline No & 120 & $28.9 \%$ \\
\hline \multicolumn{3}{|l|}{ Time taken to reach the OPD } \\
\hline Less than or equal to 1 hour & 256 & $61.7 \%$ \\
\hline More than 1 hour & 159 & $38.3 \%$ \\
\hline \multicolumn{3}{|l|}{ Money spent to reach the OPD } \\
\hline 10 birr and less & 187 & $45.1 \%$ \\
\hline Greater than 10 birr & 228 & $54.9 \%$ \\
\hline \multicolumn{3}{|l|}{ Waiting time to see the doctor } \\
\hline Less than or equal to 1 hour & 232 & $55.9 \%$ \\
\hline More than one hour & 183 & $44.1 \%$ \\
\hline \multicolumn{3}{|c|}{ The total time of spent to getting complete health services } \\
\hline Less than or equal to 2 hour & 48 & $11.6 \%$ \\
\hline More than two hour & 367 & $88.4 \%$ \\
\hline \multicolumn{3}{|l|}{ Schedule of working hour of OPD is adequate } \\
\hline Yes & 185 & $44.6 \%$ \\
\hline No & 230 & $55.4 \%$ \\
\hline
\end{tabular}

highest overall score of satisfaction was registered for pharmacy services (86.15\%) and the lowest score was attained by patient registration services (Table 5).

\section{Discussion and Conclusion}

The overall satisfaction level of outpatient service users in the study area was 58.3\% (242). This finding was lower than research reports from Ethiopia (89.1\%) in Jimma [7] and 80.1\% in Hawassa [8], and abroad having overall patient satisfaction of 75.08\% in Tertiary Care Hospital in Nagpur [4], 66.8\% in Southeastern Nigeria [5].

These studies were about over all patient satisfaction, and our study was about satisfaction level of chronic illness patients. Therefore, the deference could be attributed to the fact that the health system in low income countries including Ethiopia is not prepared to provide care to chronic illness patients such as hypertension, diabetics etc. It is rather prepared for acute infectious and parasitic diseases. Therefore, patients with chronic illness do not get appropriate care.

For instance, recently we conducted clinical audit on care of diabetic patients in the same hospital. The most outstanding finding of the study was that in all 341 diabetic patient case notes reviewed we found even no single record about weight, height, and body mass index let alone, regular check up of eye, foot, lipid profile, glycated hemoglobin, and microalbuminamia (Gedefaw M. unpublished). Hence, they are very much dissatisfied than any other patient category receiving care in the hospital. 
Table 4. Patient satisfaction towards OPD health care services at FHRH, Bahir Dar City, Northwestern Ethiopia, 2012.

\begin{tabular}{|c|c|c|c|c|c|c|}
\hline \multirow{2}{*}{ No } & \multirow{2}{*}{ Variables } & \multicolumn{5}{|c|}{ Level of satisfaction $(n=415)$} \\
\hline & & $5=\mathrm{SAC}$ & $4=A G$ & $3=\mathbf{N A G}$ & 2 = DAG & $1=$ SDAG \\
\hline \multicolumn{7}{|c|}{ Physical facilities } \\
\hline 1 & Building of this hospital is clean & $50(12.1 \%)$ & $175(42.2 \%)$ & $62(14.9 \%)$ & $108(26 \%)$ & $20(4.8 \%)$ \\
\hline 2 & Ventilation inside the hospital is good & $35(8.4 \%)$ & $144(34.7 \%)$ & $122(29.4 \%)$ & $88(21.2 \%)$ & $26(6.3 \%)$ \\
\hline 3 & $\begin{array}{l}\text { Enough light inside the building } \\
\text { of hospital }\end{array}$ & $54(13 \%)$ & $174(41.8 \%)$ & $114(27.5 \%)$ & $60(14.5 \%)$ & $13(3.2 \%)$ \\
\hline 4 & Noise around the hospital & $37(8.9 \%)$ & $162(39 \%)$ & $103(24.8 \%)$ & $85(20.6 \%)$ & $28(6.7 \%)$ \\
\hline 5 & Waiting room has enough sitting chairs & $30(7.2 \%)$ & $60(14.5 \%)$ & $78(18.8)$ & $200(48.2 \%)$ & $47(11.3 \%)$ \\
\hline 6 & Enough clean toilets are available & $6(1.5 \%)$ & $26(6.3 \%)$ & $52(12.5 \%)$ & 228 (54.9\%) & $103(24.8 \%)$ \\
\hline 7 & Enough examination rooms are available & $17(4.1 \%)$ & 77 (18.6\%) & $100(24.1 \%)$ & $135(32.5 \%)$ & $86(20.7 \%)$ \\
\hline \multicolumn{7}{|c|}{ Medical equipment } \\
\hline 8 & $\begin{array}{l}\text { Enough medical equipment for } \\
\text { examination is available }\end{array}$ & $14(3.4 \%)$ & $35(8.4 \%)$ & $84(20.2 \%)$ & 224 (54\%) & $58(14 \%)$ \\
\hline 9 & $\begin{array}{l}\text { Supplies of medical equipment are } \\
\text { always available }\end{array}$ & $5(1.2 \%)$ & $30(7.2 \%)$ & $91(21.9 \%)$ & $197(47.5 \%)$ & $92(22.2 \%)$ \\
\hline \multicolumn{7}{|c|}{ Doctor services } \\
\hline 10 & $\begin{array}{l}\text { Hospital doctors do physical } \\
\text { examination with respect }\end{array}$ & $88(21.2 \%)$ & 228 (54.9\%) & $51(12.3 \%)$ & $34(8.2 \%)$ & $14(3.4 \%)$ \\
\hline 11 & Doctors spend enough time to patient & $55(13.2 \%)$ & $199(48 \%)$ & $87(21 \%)$ & $55(13.2 \%)$ & $19(4.6 \%)$ \\
\hline \multicolumn{7}{|c|}{ Nurse services } \\
\hline 12 & $\begin{array}{l}\text { Hospital nurses treat the patient } \\
\text { with respect }\end{array}$ & $66(15.9 \%)$ & $180(43.4 \%)$ & $84(20.2 \%)$ & $59(14.2 \%)$ & $26(6.3 \%)$ \\
\hline 13 & Nurses explain the treatment clearly & $44(10.6 \%)$ & 182 (43.9\%) & $82(19.8 \%)$ & 79 (19\%) & $28(6.7 \%)$ \\
\hline \multicolumn{7}{|c|}{ Pharmacy services } \\
\hline 14 & $\begin{array}{l}\text { Hospital pharmacists treat the patient } \\
\text { with respect. }\end{array}$ & $138(33.3 \%)$ & $178(42.9 \%)$ & $45(10.8 \%)$ & $37(8.9 \%)$ & $17(4.1 \%)$ \\
\hline 15 & $\begin{array}{l}\text { Pharmacists explain the use of } \\
\text { medicine clearly }\end{array}$ & 91 (21.9\%) & $196(47.2 \%)$ & $67(16.2 \%)$ & $46(11.1 \%)$ & $15(3.6 \%)$ \\
\hline \multicolumn{7}{|c|}{ Registration services } \\
\hline 16 & $\begin{array}{l}\text { Registration staffs treat the patient } \\
\text { with respect }\end{array}$ & $26(6.3 \%)$ & $116(28 \%)$ & $54(13 \%)$ & $153(36.8 \%)$ & $66(15.9 \%)$ \\
\hline 17 & $\begin{array}{l}\text { Registration staffs have good } \\
\text { communication skill }\end{array}$ & $19(4.6 \%)$ & $84(20.2 \%)$ & 91 (21.9\%) & $141(34 \%)$ & $80(19.3 \%)$ \\
\hline \multicolumn{7}{|c|}{ Expense for laboratory tests } \\
\hline 18 & $\begin{array}{l}\text { Expenses for pathology laboratory } \\
\text { tests are affordable }\end{array}$ & $25(6 \%)$ & $83(20 \%)$ & $98(23.6 \%)$ & $168(40.5 \%)$ & $41(9.9 \%)$ \\
\hline 19 & $\begin{array}{l}\text { Medical expenses for X-ray laboratory } \\
\text { tests are affordable }\end{array}$ & $17(4.1 \%)$ & $87(21 \%)$ & $101(24.3 \%)$ & $154(37.1 \%)$ & $56(13.5 \%)$ \\
\hline
\end{tabular}

*SAG: strongly agree; AG: agree; NAG: not agree; DAG: disagree; SDAG: strongly disagree.

To put it in a nut shell, more than $40 \%$ of the patients were not satisfied with the service. This is totally unacceptable care for a regional referral hospital situated in the capital city of a region home for more than 20 million 
Table 5. Number and percentage distribution overall satisfaction.

\begin{tabular}{|c|c|c|c|c|}
\hline \multirow{3}{*}{ Variables } & \multicolumn{4}{|c|}{ Level of satisfaction $n=415$} \\
\hline & \multicolumn{2}{|c|}{ Satisfied } & \multicolumn{2}{|c|}{ Not satisfied } \\
\hline & $\mathbf{N}$ & $\%$ & $\mathbf{N}$ & $\%$ \\
\hline Physical facilities & 257 & 62.05 & 158 & 37.95 \\
\hline Medical equipment & 140 & 33.75 & 275 & 66.25 \\
\hline Doctor services & 293 & 70.6 & 122 & 29.4 \\
\hline Nurse services & 318 & 76.85 & 97 & 23.15 \\
\hline Pharmacy services & 358 & 86.15 & 57 & 13.85 \\
\hline Registration services & 195 & 46.95 & 220 & 53.05 \\
\hline Expense for laboratory tests & 205 & 49.5 & 210 & 50.5 \\
\hline
\end{tabular}

people. Therefore, there is a need to revisit care given to chronic illness patients, and appropriate strategy should be designed to address the lifelong care needs of patients with chronic illness in our set up.

\section{Acknowledgment}

We would like to thank GAMBY College of Medical sciences, Bahir Dar University, and administrators of Felege Hiwot Referral Hospital. We are also obliged to tank the study participants

\section{References}

[1] Kravitz, R. (1998) Patient Satisfaction with Health Care. Journal of General Internal Medicine, 13, $280-282$. http://dx.doi.org/10.1046/j.1525-1497.1998.00084.X

[2] Assefa, F., Mosse, A. and Hailemichael, Y. (2011) Assessment of Clients' Satisfaction with Health Service Deliveries at Jimma University Specialized Hospital. Ethiopian Journal of Health Sciences, 21, 101-109. http://dx.doi.org/10.4314/ejhs.v21i2.69050

[3] Larsen, D.E. and Rootman, R. (1976) Physician's Role Performance and Patient Satisfaction. Social Science Medicine, 10, 29-32. http://dx.doi.org/10.1016/0037-7856(76)90136-0

[4] Kulkarni, M.V., Dasgupta, S., Deoke, A.R. and Nayse (2011) Study of Satisfaction of Patients Admitted in a Tertiary Care Hospital in Nagpur. National Journal of Community Medicine, 2, 37-39.

[5] Iloh, G., Ofoedu, J.N., Njoku, P.U., Odu, F.U., Ifedigbo, C.V. and Iwuamanam, K.D. (2012) Evaluation of Patients' Satisfaction with Quality of Care Provided at the National Health Insurance Scheme Clinic of a Tertiary Hospital in South-Eastern Nigeria. Niger Journal of Clinical Practice, 15, 69-74. http://dx.doi.org/10.4103/1119-3077.104529

[6] Lumadi, T.G. and Buch, E. (2011) Patients' Satisfaction with Midwifery Services at a Regional Hospital and Its Referring Clinics in the Limpopo Province of South Africa. Africa Journal of Nursing and Midwifery, 13, 14-28.

[7] Beyene, W., Jira, C. and Sudhakar, M. (2011) Assessment of Quality of Health Care in Jimma Zone, Southwest Ethiopia. Ethiopian Journal of Health Sciences, 21, 49-58.

[8] Asefa, A., Kassa, A. and Dessalegn, M. (2014) Patient Satisfaction with Outpatient Health Services in Hawassa University Teaching Hospital, Southern Ethiopia. Journal of Public Health and Epidemiology, 6, 101-110. http://dx.doi.org/10.5897/JPHE2013.0613

[9] Abdosh, B. (2006) The Quality of Hospital Services in Eastern Ethiopia: Patient's Perspective. Ethiopian Journal of Health Development, 20, 199-200.

[10] Tateke, T., Woldie, M. and Ololo, S. (2012) Determinants of Patient Satisfaction with Outpatient Health Services at Public and Private Hospitals in Addis Ababa, Ethiopia. Journal of Family Medicine and Primary Care, 4, 1-11. http://dx.doi.org/10.4102/phcfm.v4i1.384

[11] Adane, G. (2006) Assessment of Client Satisfaction with Outpatient Services in Tigray Zonal Hospitals. Master's Thesis: (Unpublished Document). 
Scientific Research Publishing (SCIRP) is one of the largest Open Access journal publishers. It is currently publishing more than 200 open access, online, peer-reviewed journals covering a wide range of academic disciplines. SCIRP serves the worldwide academic communities and contributes to the progress and application of science with its publication.

Other selected journals from SCIRP are listed as below. Submit your manuscript to us via either submit@scirp.org or Online Submission Portal.
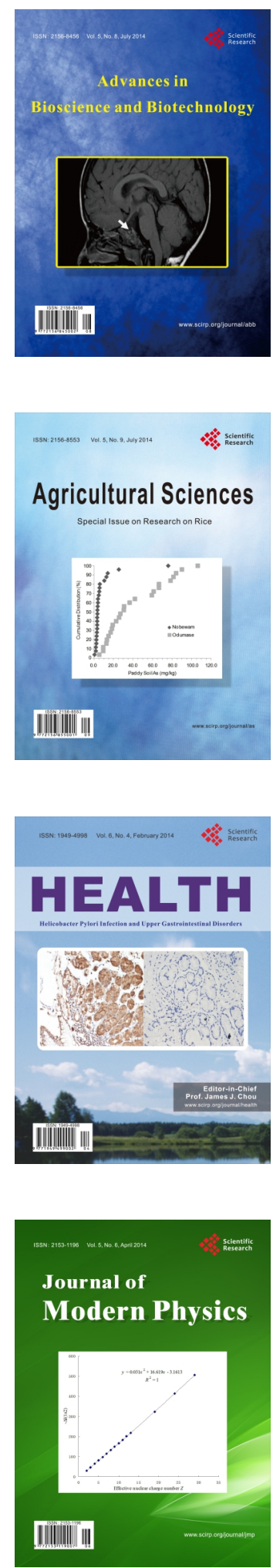
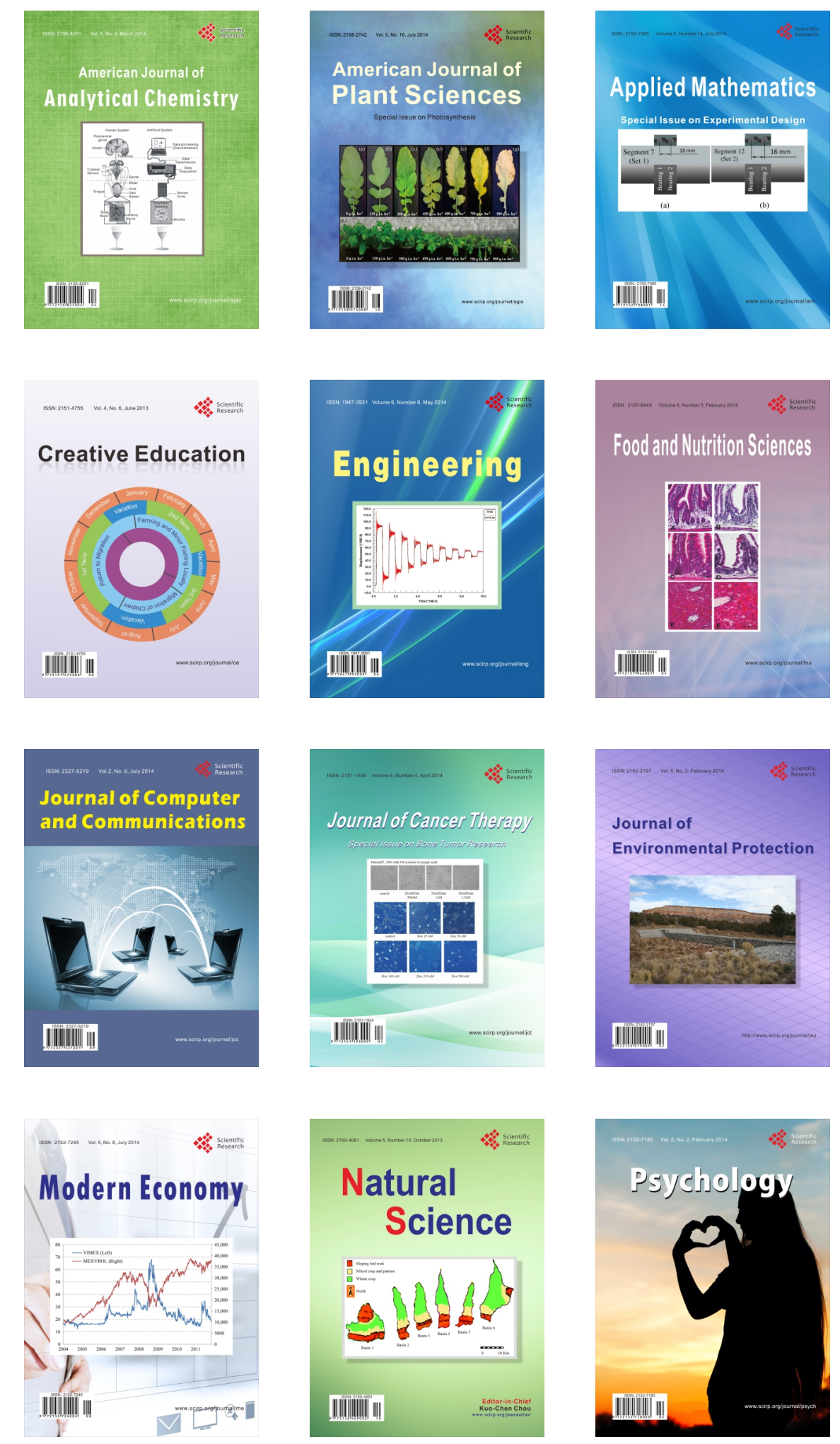